\title{
Insulin Resistance Is Associated with Reduced Fasting and Insulin-stimulated Glycogen Synthase Phosphatase Activity in Human Skeletal Muscle
}

\author{
Yasuo Kida, Antonella Esposito-Del Puente, Clifton Bogardus, and David M. Mott \\ Clinical Diabetes and Nutrition Section, National Institute of Diabetes and Digestive and Kidney Diseases, \\ National Institutes of Health, Phoenix, Arizona 85016
}

\begin{abstract}
Insulin-stimulated glycogen synthase activity in human skeletal muscle correlates with insulin-mediated glucose disposal rate $(M)$ and is reduced in insulin-resistant subjects. We have previously reported reduced insulin-stimulated glycogen synthase activity associated with reduced fasting glycogen synthase phosphatase activity in skeletal muscle of insulin-resistant Pima Indians. In this study we investigated the time course for insulin stimulation of glycogen synthase and synthase phosphatase during a 2-h high-dose insulin infusion (600 $\mathrm{mU} / \mathrm{min}$ per $\mathrm{m}^{2}$ ) in six insulin-sensitive caucasians (group $\mathrm{S}$ ) and in five insulin-resistant Pima Indians (group R). Percutaneous muscle biopsies were obtained from the quadriceps femoris muscle after insulin infusion for $0,10,20,40$, and $120 \mathrm{~min}$.

In group $S$, insulin-stimulated glycogen synthase activity increased with time and was significantly higher than in group R. In group S, synthase phosphatase activity increased signifcantly by $25 \%$ at 10 min and then decreased gradually. No significant change in synthase phosphatase was seen in group $R$ and activity was lower than group $S$ at 0 to $20 \mathrm{~min}$.

These data suggest that a low basal synthase phosphatase activity and a defect in its response to insulin explain, at least in part, reduced insulin stimulation of skeletal muscle glycogen synthase associated with insulin resistance. (J. Clin. Invest. 1990. 85:476-481.) insulin • glycogen synthase $\bullet$ protein phosphatase $\bullet$ muscle
\end{abstract}

\section{Introduction}

Glucose storage via glycogen synthesis in skeletal muscle is a major determinant of whole-body insulin-mediated glucose disposal in man (1-3). A rate-limiting enzyme in glycogen synthesis is glycogen synthase, which is regulated by both covalent phosphorylation-dephosphorylation and allosteric modifications (4-7). Phosphorylation (inactivation) of glycogen synthase is catalyzed by several different protein kinases acting on different phosphorylation sites (8-10), while the reverse reaction (activation) is catalyzed by protein phosphatases $(11,12)$. Insulin administration results in a rapid increase in the percentage of synthase in the dephosphorylated (glucose6-phosphate, $\mathrm{G}^{\mathrm{P}} \mathrm{P}^{1}$-independent) form and stimulates glycogen synthesis in both animal and human tissues $(1,3,14-18)$.

Address reprint requests to Dr. Mott, Clinical Diabetes and Nutrition Section, National Institutes of Health, 4212 N. 16th St., Room 541, Phoenix, AZ 85016.

Received for publication 11 July 1989 and in revised form.

1. Abbreviations used in this paper: G6P, glucose-6-phosphate; $\mathrm{M}$, insulin-stimulated glucose disposal rate.

The Journal of Clinical Investigation, Inc.

Volume 85, February 1990, 476-481
However, the mechanism by which insulin stimulates the conversion of synthase to the dephosphorylated form is unclear in human skeletal muscle. It could result from a decrease in protein kinase activity and/or an increase in synthase phosphatase activity $(5-8,11)$. Several animal studies have suggested that insulin stimulation of glycogen synthase is associated with activation of synthase phosphatase $(16,19)$. However, insulinmediated changes of synthase phosphatase activity have not been demonstrated in human tissues.

In this study, we investigated the time course for insulinmediated regulation of both glycogen synthase and synthase phosphatase during a hyperinsulinemic, euglycemic clamp in human skeletal muscle from insulin-sensitive and insulin-resistant subjects.

\section{Methods}

Subjects. Six insulin-sensitive caucasians (group S) and five insulin-resistant Pima Indians (group R) participated in this study. These subjects were selected to have a glucose disposal rate that was significantly lower in group $R$ than in group $S$ (Table I). Age, body weight, percent body fat, fasting plasma glucose, and fasting plasma insulin concentrations of the two groups are also shown in Table I. Body weight, body fat, and fasting insulin were significantly higher in group $R$ than in group $S$ (each $P<0.001$ ).

Informed consent was obtained and fitness for the study was determined by medical history, physical examination, electrocardiography, and routine blood biochemical and hematological testing. None of the subjects were taking any medication and no subject had any abnormalities on these examinations. After consuming a weight maintaining diet (20\% protein, $50 \%$ carbohydrate, and $30 \%$ fat) for at least $2 \mathrm{~d}$, each subject had a 75-g oral glucose tolerance test. None of the subjects had diabetes mellitus but three in group $\mathbf{R}$ had impaired glucose tolerance according to the criteria established by the National Diabetes Data Group (20). After at least $3 \mathrm{~d}$ on a weight maintenance diet, a hyperinsulinemic, euglycemic clamp (1) was performed. Body fat was estimated by underwater weighing with simultaneous measurement of residual lung volume (21).

Euglycemic clamp (Fig. 1). After an overnight fast, an intravenous catheter was placed in the antecubital vein for infusion of insulin and glucose. Another catheter was inserted retrograde in a dorsal hand vein of the contralateral hand for blood withdrawal and this hand was kept in a warming box $\left(70^{\circ} \mathrm{C}\right)$ during the entire clamp procedure for venous blood arterialization. The clamp was initiated by a primed-continuous high-dose insulin infusion $\left(600 \mathrm{mU} / \mathrm{min}\right.$ per $\left.\mathrm{m}^{2}\right)$ for $120 \mathrm{~min}$. After the start of the insulin infusion, a variable infusion of $20 \%$ glucose was given as necessary to maintain the plasma glucose concentration at 100 $\mathrm{mg} / \mathrm{dl}$ for all subjects. The plasma insulin concentration was determined before the start of the insulin infusion and at 10, 20, 40, 60, 80, and 120 min during the clamp. The plasma glucose was determined before the start of insulin infusion and every 2.5-5 min through the end of the clamp. Insulin-stimulated glucose disposal rate (M) was determined during the 80 - to 120 -min period. The steady-state plasma insulin and glucose concentrations were $\sim 2,700 \mu \mathrm{U} / \mathrm{ml}$ and 100 $\mathrm{mg} / \mathrm{dl}$, respectively, in both groups (Table II). Plasma glucose concentration was measured by the glucose oxidase method using a glucose analyzer (Beckman Instruments, Inc., Fullerton, CA). Plasma insulin 
Table I. Subjects' Characteristics

\begin{tabular}{|c|c|c|c|c|c|c|c|}
\hline \multirow[b]{2}{*}{ No. } & \multirow[b]{2}{*}{ Sex } & \multirow[b]{2}{*}{ Age } & \multirow{2}{*}{$\begin{array}{l}\text { Body } \\
\text { weight }\end{array}$} & \multirow{2}{*}{$\begin{array}{l}\text { Body } \\
\text { fat }\end{array}$} & \multirow{2}{*}{$\begin{array}{l}\text { Glucose disposal } \\
\text { rate }\end{array}$} & \multicolumn{2}{|c|}{ Fasting plasma } \\
\hline & & & & & & Glucose & Insulin \\
\hline & & $y r$ & $k g$ & $\%$ & $\mathrm{mg} / \mathrm{kg}-\mathrm{FFM} / \mathrm{min}$ & $m g / d l$ & $\mu U / m$ \\
\hline 1 & $\mathbf{M}$ & 25 & 70.5 & 6 & 14.2 & 84 & 7 \\
\hline 2 & $\mathrm{~F}$ & 28 & 56.1 & 20 & 9.3 & 89 & 4 \\
\hline 3 & $\mathbf{M}$ & 21 & 82.4 & 18 & 13.4 & 88 & 3 \\
\hline 4 & $\mathbf{M}$ & 27 & 68.0 & 15 & 11.6 & 90 & 6 \\
\hline 5 & $\mathbf{M}$ & 19 & 65.8 & 11 & 13.5 & 77 & 4 \\
\hline 6 & $\mathbf{M}$ & 21 & 67.6 & 13 & 12.8 & 91 & 6 \\
\hline \multicolumn{8}{|l|}{ Group S } \\
\hline mean $\pm S E$ & & $24 \pm 2$ & $68.4 \pm 3.5^{*}$ & $14 \pm 2 *$ & $12.5 \pm 0.7^{*}$ & $87 \pm 2$ & $5 \pm 1^{*}$ \\
\hline 1 & $\mathbf{F}$ & 19 & 123.3 & 42 & 5.5 & 88 & 37 \\
\hline 2 & $\mathbf{M}$ & 26 & 113.8 & 36 & 6.7 & 92 & 30 \\
\hline 3 & $\mathbf{M}$ & 43 & 147.9 & 42 & 5.3 & 106 & 43 \\
\hline 4 & $\mathbf{F}$ & 37 & 111.0 & 47 & 7.5 & 99 & 30 \\
\hline 5 & $F$ & 33 & 117.6 & 41 & 4.6 & 128 & 35 \\
\hline $\begin{array}{l}\text { Group } R \\
\text { mean } \pm \text { SE }\end{array}$ & & $32 \pm 4$ & $122.7 \pm 6.6$ & $42 \pm 2$ & $5.9 \pm 0.5$ & $103 \pm 7$ & $35 \pm 2$ \\
\hline
\end{tabular}

Three subjects $(3,4$, and 5$)$ in group $R$ were impaired glucose tolerant. $T$ test: ${ }^{*} P<0.001$ between groups.

concentrations were determined using a radioassay analyzer (Concept 4; ICN, Horsham, PA).

Muscle biopsy. Before the start of insulin infusion and at the indicated timepoints (Fig. 1), percutaneous muscle biopsies were taken from the quadriceps femoris muscle after local anesthesia of skin and fascia. Specimens (80-120 mg) were collected within 5 min using the Bergström needle (Depuy, Phoenix, AZ). The first biopsy site was 35\% of the distance from the superior margin of the patella to the anterior superior iliac spine in the right thigh. The second through fifth biopsies were taken at 10,20, 40, and 120 min during the clamp. Biopsy sites for the second through fifth biopsies were as follows: the same location relative to the patella in the left thigh, $2 \mathrm{~cm}$ caudal from the first biopsy, $2 \mathrm{~cm}$ caudal from the second biopsy, and $4 \mathrm{~cm}$ caudal from the first biopsy, respectively. The biopsy specimens were frozen in liquid nitrogen within $15 \mathrm{~s}$ and stored at $-70^{\circ} \mathrm{C}$.

Enzyme assay. The biopsies were lyophilized, dissected free of blood, fat, and all visible connective tissue, and powdered. The powder was thoroughly mixed and stored at $-70^{\circ} \mathrm{C}$ until analysis.

Glycogen synthase activity was determined with the following modification of the method of Guinovart (22) and Thomas (23). Briefly, dry muscle powder was weighed and homogenized in a $30 \%$ glycerol, $10 \mathrm{mM}$ EDTA, and $50 \mathrm{mM}$ potassium fluoride (KF) (pH 7) solution (200 $\mu \mathrm{l} / \mathrm{mg}$ dry $w \mathrm{t})$ using a ground glass tissue grinder (Rad-

MEASUREMENT OF GLUCOSE DISPOSAL RATE

INSULIN INFUSION $600 \mathrm{mU} / \mathrm{min} / \mathrm{m}^{2}$

MUSCLE BIOPSY

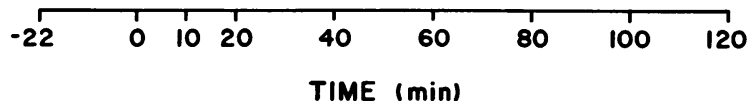

Figure 1. Synoptic diagram of the hyperinsulinemic, euglycemic clamp. Muscle biopsies were taken at $0,10,20,40$, and 120 min during the clamp. Glucose disposal rates were determined for the 40 min period between 80 and $120 \mathrm{~min}$. noti Glass Technology, Inc., Monrovia, CA) at $4^{\circ} \mathrm{C}$. The homogenate was centrifuged at $10,000 \mathrm{~g}$ for $20 \mathrm{~min}$ at $4^{\circ} \mathrm{C}$. $100 \mu \mathrm{l}$ supernatant was diluted with $500 \mu \mathrm{l}$ of a buffer containing $50 \mathrm{mM}$ Tris, $20 \mathrm{mM}$ EDTA, and $130 \mathrm{mM} \mathrm{KF}\left(\mathrm{pH} \mathrm{7.8)}\right.$ at $4^{\circ} \mathrm{C}$ and used for glycogen synthase assay. The active form of glycogen synthase was assayed at $0.17 \mathrm{mM} \mathrm{G6P}$ and total glycogen synthase activity was assayed at a $7.2 \mathrm{mM}$ G6P. Fractional activity of glycogen synthase was expressed as the activity ratio of active form to total glycogen synthase. The assay used $0.13 \mathrm{mM}$. UDP-glucose and $4.7 \mathrm{mg} / \mathrm{ml}$ glycogen. Activities are expressed as units per gram of tissue dry weight. $1 \mathrm{U}$ equals micromoles of $\left[{ }^{14} \mathrm{C}\right]$ glucose incorporation into glycogen per minute at $30^{\circ} \mathrm{C}$. G6P and UDP-glucose were purchased from Sigma Chemical Co. and $\left[{ }^{14} \mathrm{C}\right] \mathrm{UDP}$-glucose from New England Nuclear (Boston, MA).

Glycogen synthase phosphatase was assayed according to the method of Miller (24) with some modification. The homogenate was prepared with $16 \mu \mathrm{l}$ buffer/mg dry wt according to the method of Chang and Huang (16). Briefly, powder was homogenized with $50 \mathrm{mM}$ Tris, $10 \mathrm{mM}$ EDTA, and $50 \mathrm{mM}$ 2-mercaptoethanol (pH 7.8) using a glass tissue grinder at $4^{\circ} \mathrm{C}$. The homogenate was centrifuged at 17,000 $g$ for $10 \mathrm{~min}$ at $4^{\circ} \mathrm{C}$. The supernatant was incubated for $5 \mathrm{~min}$ at $30^{\circ} \mathrm{C}$ with purified (13) rabbit glycogen synthase D (44 mU GSD/assay; Sigma Chemical Co., St. Louis, MO) in $10 \mathrm{mM}$ Tris, $1 \mathrm{mM}$ EDTA, and $5 \mathrm{mM}$ dithiothreitol buffer, which was preincubated for $5 \mathrm{~min}$ at $30^{\circ} \mathrm{C}$. Synthase phosphatase activity was determined from the change in the active form of glycogen synthase per minute and expressed as units per gram dry weight.

Both glycogen synthase and synthase phosphatase activities were linear with time within the limits described for each assay. Preliminary studies demonstrated that the activities of these enzymes were not altered by the lyophilization procedure. The average (range) of dry muscle weight was $23 \%$ (22-24\%) of wet weight. The contents of nonmuscle constituents were variable from sample to sample with an average of $7 \%(2-25 \%)$ of dry weight. Interassay variations of glycogen synthase and synthase phosphatase activities were $5 \%$ and $8 \%$, respectively, and were smaller than those using wet muscle (data not shown).

Muscle G6P and ATP were determined for five subjects in group S and four in group $R$ using the change in NADP-NADPH associated fluorescence after the addition of G6P dehydrogenase and hexokinase (G5760 and H1131 from Sigma Chemical Co.) after 0.5 M perchloric acid extractions (25). Interassay variations of G6P and ATP were both $5 \%$.

Statistics. Significance $(P<0.05)$ of the differences were analyzed with Student's paired or nonpaired $t$ test. All data were expressed as mean \pm SE unless otherwise indicated.

\section{Results}

The activities of glycogen synthase and synthase phosphatase during insulin infusion are shown in Fig. 2. Total glycogen synthase activity was significantly higher in group $S$ than in group $\mathrm{R}$ at time 0 and $120 \mathrm{~min}$ (both $P<0.05$ ). In group $\mathrm{S}$, total glycogen synthase activity significantly increased at 120 min $(P<0.05)$, whereas no significant change occurred in group $\mathrm{R}$ (Fig. $2 A$ ). Before the insulin infusion, glycogen synthase fractional activity was not significantly different between the two groups. However, in group $S$ the $10-\mathrm{min}$ fractional activity was significantly higher than in group $\mathrm{R}(P<0.05)$ and remained significantly stimulated above basal from $10 \mathrm{~min}$ to the end of the clamp $(P<0.01$ at 10 and $20 \mathrm{~min}, P<0.001$ at 40 and $120 \mathrm{~min}$ ). In group $\mathrm{R}$, a significant increase in fractional activity was not observed before $20 \mathrm{~min}$, but remained significantly stimulated above basal for the duration of insulin infusion (Fig. $2 \mathrm{~B}$ ). The active form of glycogen synthase showed similar results. In group $S$, glycogen synthase activity at all timepoints after insulin infusion was significantly higher than in group $\mathrm{R}$ (Fig. 2 C). 
Table II. Plasma Glucose and Insulin Concentrations during Clamp

\begin{tabular}{|c|c|c|c|c|c|c|c|c|}
\hline Time (min) & n) 0 & 10 & 20 & 40 & 60 & 80 & 100 & 120 \\
\hline \multicolumn{9}{|c|}{ Plasma glucose $(m g / d l)^{*}$} \\
\hline Group S & $100 \pm 1$ & $102 \pm 2$ & $95 \pm 3$ & $99 \pm 3$ & $101 \pm 3$ & $102 \pm 2$ & $102 \pm 3$ & $99 \pm 2$ \\
\hline Group R & $102 \pm 2$ & $105 \pm 3$ & $106 \pm 9$ & $111 \pm 10$ & $99 \pm 1$ & $100 \pm 2$ & $99 \pm 1$ & $99 \pm 2$ \\
\hline \multicolumn{9}{|c|}{ Plasma insulin $(\mu U / m l)^{\ddagger}$} \\
\hline Group S & $5 \pm 1^{\S}$ & $1,517 \pm 65$ & $1,748 \pm 112$ & $2,043 \pm 169$ & $2,410 \pm 229$ & $2,669 \pm 282$ & - & $2,781 \pm 383$ \\
\hline Group R & $34 \pm 2$ & $1,598 \pm 39$ & $1,721 \pm 51$ & $2,092 \pm 148$ & $2,265 \pm 66$ & $2,584 \pm 154$ & - & $2,942 \pm 137$ \\
\hline
\end{tabular}

* Mean \pm SE of samples drawn at 2.5 - to 5-min intervals using a 20 -min interval before indicated times. ${ }^{\ddagger}$ Mean \pm SE of samples drawn at indicated times. ${ }^{8} t$ test: $P<0.001$ between groups.

Synthase phosphatase activity was significantly higher in group $S$ than in group $\mathrm{R}$ at 0,10 , and $20 \mathrm{~min}(P<0.01)$. In group $S$, synthase phosphatase activity increased by $25 \%$ at 10 $\min (P<0.01)$ and then returned to the basal level by $40 \mathrm{~min}$. At the end of the clamp, the activity was significantly lower than the basal $(P<0.01)$. In group $\mathrm{R}$ no significant change in mean synthase phosphatase activity was observed during the clamp (Fig. $2 \mathrm{D}$ ).

The changes of synthase phosphatase activities during the clamp are shown for each subject in Fig. 3. In group $\mathrm{S}$, all six

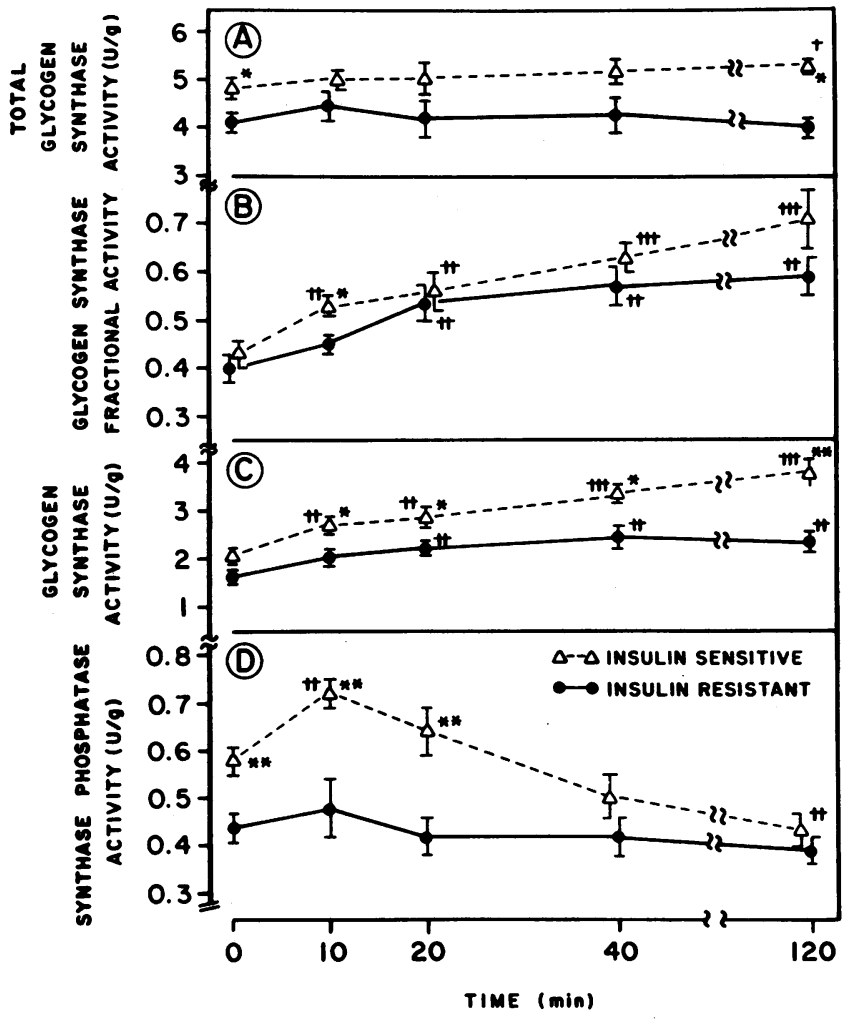

Figure 2. Change of total glycogen synthase activity $(A)$; glycogen synthase fractional activity $(B)$; active form of glycogen synthase activity $(C)$; and synthase phosphatase activity $(D)$ in group $S(\Delta)$ and group $\mathbf{R}(\bullet)$. Glycogen synthase and synthase phosphatase activities were measured as described in Methods. Results are expressed as means \pm SE. $T$-test: ${ }^{*} P<0.05,{ }^{* *} P<0.01$ between groups. Paired $t$ test: $+P<0.05,++P<0.01,+++P<0.001$ vs. 0 min. subjects showed an increase in activity at $10 \mathrm{~min}$ and five were maximally activated at $10 \mathrm{~min}$ (Fig. $3 \mathrm{~A}$ ). In group $\mathrm{R}$ the results were variable (Fig. $3 \mathrm{~B}$ ). Only two of the five subjects showed activation at $10 \mathrm{~min}$ and two subjects did not show any increase in the activity during the clamp. The maximumstimulated activity of each subject in group $R$ fell below the range for stimulated activity in group $S$. In group $S$, only the phosphatase activity at $\mathbf{0}$ min was significantly correlated with insulin-mediated glucose disposal rates $(r=0.9, P<0.05)$. Phosphatase activity at $0 \mathrm{~min}$ was not significantly correlated

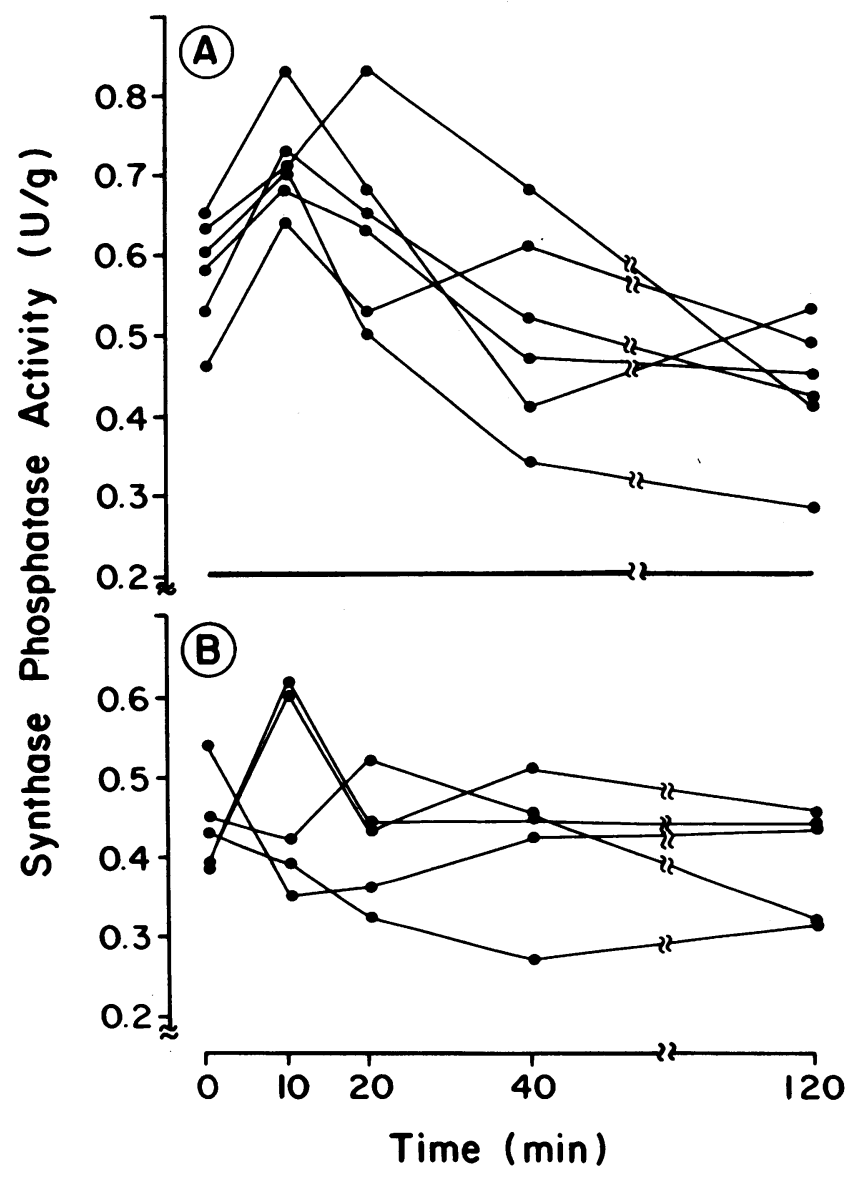

Figure 3. Individual synthase phosphatase activities at each timepoint in group $\mathrm{S}(A)$ and group $\mathrm{R}(B)$. 
with percent body fat $(r=0.7, P=0.09)$. In group $\mathrm{R}$, phosphatase activity was not correlated with glucose disposal or with percent body fat.

Mean G6P concentrations (micromoles per gram) from $\mathbf{0}$, $10,20,40$, and $120 \mathrm{~min}$ were $1.03 \pm 0.16,1.14 \pm 0.21$, $1.45 \pm 0.45,1.30 \pm 0.25$, and $1.89 \pm 0.52$ in group $S$ and $1.53 \pm 0.34,1.20 \pm 0.16,1.18 \pm 0.29,1.36 \pm 0.52$, and $1.82 \pm 0.29$ in group R. Mean ATP concentrations (micromoles per gram) at each timepoint ranged from $25.5 \pm 2.1$ to $27.0 \pm 3.5$ in group $\mathrm{S}$ and $21.1 \pm 3.9$ to $22.2 \pm 3.8$ in group $\mathrm{R}$. There was no significant change in either G6P or ATP concentrations during insulin infusion in these subjects and there was no significant difference in both basal and insulin-stimulated G6P and ATP between groups.

\section{Discussion}

We have reported a positive correlation between insulin-stimulated glucose disposal rate (M) and insulin-stimulated skeletal muscle glycogen synthase activity in vivo in man and suggested that the regulation of glycogen synthase may contribute to the reduced glucose disposal associated with insulin resistance in Southwestern American Indians $(1,3)$. A similar conclusion was reached in an in vivo study of normal glucose tolerant caucasians (26).

Glycogen synthase data in the present study reconfirmed the association of impaired activation of insulin-stimulated glycogen synthase with insulin resistance in Southwestern American Indians. Although the basal glycogen synthase activities (Fig. $2 C$ ) between the two groups did not differ significantly, basal total glycogen synthase activities (Fig. $2 A$ ) were significantly lower in group $R$ and there was no increase in the mean total activity during the 120 -min clamp. This is in contrast to the significant increase in total glycogen synthase activities after $120 \mathrm{~min}$ of insulin infusion in group $\mathrm{S}$. Freymond et al. (14) also reported a significant increase in total glycogen synthase activity at the end of a 460-min insulin infusion in man. Pain et al. (27) reported decreased protein synthesis in skeletal muscle using streptozotocin-diabetic rats. Goheer et al. (28) also reported a significant increase of total glycogen synthase in $\mathrm{H} 4$ cells after $1 \mathrm{~h}$ incubation with physiological concentrations of insulin. Therefore, lower total glycogen synthase activity and a defective insulin-mediated increase of total activity in insulin-resistant subjects may be reflecting an impairment of insulin-stimulated protein synthesis in skeletal muscle. These observations suggest that reduced synthesis of glycogen synthase may contribute to the mechanisms for insulin resistance observed under these conditions.

We assayed the active form of glycogen synthase under physiological concentrations $(0.17 \mathrm{mM})$ of $\mathrm{G} 6 \mathrm{P}$ in an effort to more closely approximate in vivo activity in skeletal muscle. After insulin infusion, both the fractional (Fig. $2 B$ ) and active form (Fig. $2 C$ ) of glycogen synthase activities in group $\mathrm{S}$ increased by $10 \mathrm{~min}$ and appeared to increase through $120 \mathrm{~min}$. On the other hand, in group $\mathbf{R}$ significant changes occurred later than in group $S$ and the activities appeared to plateau after $\mathbf{4 0 ~} \mathrm{min}$. This is in spite of significant increase in plasma insulin concentrations in group $\mathrm{R}$ between 40 and $120 \mathrm{~min}(P$ $<0.001$ ) (Table II). Therefore, lower insulin-stimulated glycogen synthase activities in group $R$ were not simply due to the lower total activity but also a result of lower fractional activity.
Glycogen synthase activity is regulated by both noncovalent allosteric interaction and covalent phosphorylation/dephosphorylation (5-7). Phosphorylation states of several specific sites in the glycogen synthase molecule alter its activity $(8$, 9). It is known that insulin is a potent activator of glycogen synthase in liver, fat, and muscle, but the sequence of events leading to insulin-stimulated intracellular glycogenesis initiated by insulin is not clear in human skeletal muscle. Inhibition of phosphorylation by inactivation of protein kinases $(9$, $10)$ and/or stimulation of dephosphorylation by protein phosphatase activation $(11,16)$ have been considered as mechanisms of insulin action.

We have recently reported on synthase phosphatase activity measured before and at the end of a 460-min insulin infusion on 30 subjects with a wide range of $M$ values (14). Although the glycogen synthase activity increased after insulin infusion, the synthase phosphatase activity did not change. It was possible, however, that synthase phosphatase activation was not observed because dilution during the assay might have resulted in dissociation of presumed insulin-induced noncovalently bound regulators of phosphatase activity. Toth et al. (18) reported that insulin activated rat liver synthase phosphatase within $5 \mathrm{~min}$ using concentrated homogenates, but no hormonal effects were observed when the homogenates were diluted. They suggested that the insulin effect was mediated by a transferable cytosolic effector. In addition, we are not aware of any report on synthase phosphatase stimulation beyond 10-30 min after insulin administration. Therefore, it is possible that in our previous study (14) we missed an early change of the phosphatase activity that occurred before $460 \mathrm{~min}$.

In an attempt to answer these questions, we determined the time course of synthase phosphatase activity after a high-dose $\left(600 \mathrm{mU} / \mathrm{min}\right.$ per $\left.\mathrm{m}^{2}\right)$ insulin infusion using a homogenate that was five times more concentrated (protein concentration in assay $\sim 10 \mathrm{~g} /$ liter) than in the previous study $(13,14)$. This concentration of muscle extract was previously used by Chang and Huang (16). They demonstrated a significant increase of both glycogen synthase and synthase phosphatase at 8 and 10 min after insulin administration using rat skeletal muscle. As shown in Fig. 2, basal synthase phosphatase activity was significantly higher in group $S$ than in group $R$ and a significant increase of the activity was observed at $10 \mathrm{~min}$ only in group $S$ followed by a loss of activity in five of the six subjects (Fig. 3 $A$ ). Individual activities during the clamp plotted in Fig. $3 B$ indicate that although two subjects in group $R$ showed stimulation, the resulting phosphatase activity failed to reach the range of stimulated activity observed for the six group $\mathrm{S}$ subjects (Fig. $3 \mathrm{~A}$ ). When the individual data from both groups were considered, seven of the eight subjects showing stimulation at $10 \mathrm{~min}$ appeared to peak at $10 \mathrm{~min}$. A transient insulin-induced increase of protein phosphatase activity has also been observed in an in vitro study using 3T3 cells (29).

Several mechanisms for insulin-induced activation of synthase phosphatase can be considered: (a) G6P stimulates and ATP inhibits glycogen synthase phosphatase activity $(13,30)$. G6P has been proposed as a second messenger for insulin by Larner et al. (31); (b) inhibition of a cyclic-AMP dependent protein kinase may decrease phosphorylation of inhibitor 1 or the G-component of protein phosphatase-1 resulting in increased phosphatase activity (32-34); $(c)$ phosphorylation of inhibitor 2, a modulator protein of cytosolic protein phosphatase-1, by glycogen synthase kinase 3 and casein kinase 2 
(35-37). The first mechanism is not likely to be important. G6P determined in seven subjects (five in group $S$ and two in group $\mathbf{R}$ ) who demonstrated an activation of synthase phosphatase at 10 min shows no significant change during insulin infusion. We also determined muscle ATP concentrations in nine subjects (five in group $S$ and four in group $R$ ). Muscle ATP did not change significantly during insulin infusion. The remaining mechanisms for insulin stimulation of glycogen synthase phosphatase activity may be important in explaining the reduction in both fasting and insulin-stimulated phosphatase activity in group R. A failure of insulin to inhibit cAMPdependent protein kinase or activate casein kinase 2 or glycogen synthase kinase 3 could reduce the action of both fasting and infused insulin on phosphatase activity. Alternatively, the abnormality in fasting and insulin-stimulated total glycogen synthase activity (Fig. 2) discussed above suggests that reduced synthesis of the phosphatase could also lead to both basal and insulin-stimulated abnormalities in phosphatase activity.

Phosphatase activation was only a transient phenomenon. Activation of glycogen synthase, however, appeared to be continuous over $120 \mathrm{~min}$ of insulin infusion in insulin-sensitive subjects. This observation suggests that additional mechanism(s) exist for glycogen synthase activation during long-term insulin infusion. Insulin-induced inhibition of protein kinase activity may become important, as phosphatase activity begins to decrease. Although the mechanism that maintains the active form of glycogen synthase at $120 \mathrm{~min}$ is not clear, it is apparent that this mechanism is also abnormal in group $\mathbf{R}$ subjects. The decrease in phosphatase activity for the $S$ group at $120 \mathrm{~min}$ compared to $0 \mathrm{~min}$ may be caused by increased glycogen in the 120 -min homogenates. Although glycogen was not measured in these samples, glycogen synthesis has been demonstrated in insulin-sensitive subjects during similar insulin infusion protocols $(1,38)$ and would be expected to maintain concentrations ranging close to $0.08 \%$ (wt/vol) after dilution into the phosphatase assay. Glycogen at $0.1 \%$ has been shown to inhibit human muscle glycogen synthase phosphatase (13).

The unique characteristics of the $\mathbf{R}$ group, in addition to low insulin-mediated glucose disposal rates, are obesity and Southwestern American Indian heritage. Because the numbers of subjects in each group are small, the failure to find a significant relationship between obesity and phosphatase activity does not rule out possible effects of obesity on the activity of glycogen synthase phosphatase. Similarly, more extensive studies would be required to examine possible racial differences in phosphatase activity. Regardless of the importance of race or obesity to the insulin-resistant state studied here, it is clear that low insulin-mediated glucose uptake is also associated with abnormal activities of both synthase and phosphatase enzymes.

This is the first report that demonstrates insulin-induced activation of synthase phosphatase in human skeletal muscle. Both basal and activated synthase phosphatase activity appear to be reduced in subjects with reductions in both insulin-stimulated glycogen synthase activity and insulin-mediated glucose disposal. These data suggest that a low basal synthase phosphatase activity and a defect in its response to insulin explain, at least in part, reduced insulin stimulation of glycogen synthase in skeletal muscle associated with insulin resistance in Southwestern American Indians.

\section{Acknowledgments}

We thank the nursing staff, the dietary staff, and the technical staff for their professional assistance. We are also indebted to Susan Elson and Charlesetta Lincoln for their secretarial work. Most of all, we are grateful to the volunteers for their cooperation during the studies.

\section{References}

1. Bogardus, C., S. Lillioja, K. Stone, and D. M. Mott. 1984. Correlation between muscle glycogen synthase activity and in vivo insulin action in man. J. Clin. Invest. 73:1185-1190.

2. Lillioja, S., D. M. Mott, J. K. Zawadzki, A. A. Young, W. G. Abbott, and C. Bogardus. 1986. Glucose storage is a major determinant of in vivo "insulin resistance" in subjects with normal glucose tolerance. J. Clin. Endocrinol. Metab. 62:922-927.

3. Young, A. A., C. Bogardus, K. Stone, and D. M. Mott. 1988. Insulin response of components of whole-body and muscle carbohydrate metabolism in humans. Am. J. Physiol. 254:E231-E236.

4. Danforth, W. H. 1965. Glycogen synthase activity in skeletal muscle: interconversion of two forms and control of glycogen synthesis. J. Biol. Chem. 2:588-593.

5. Cohen, P. 1983. Protein phosphorylation and the control of glycogen metabolism in skeletal muscle. Phil. Trans. R. Soc. Lond. B302:13-25.

6. Cohen, P. 1986. Muscle glycogen synthase. In The Enzymes. Vol 17. P. D. Boyer and E. G. Krebs, editors. Academic Press, Orlando, FL. 461-497.

7. Stalmans, W., M. Bollen, and L. Mvumbi. 1987. Control of glycogen synthesis in health and disease. Diabetes/Metab. Rev. 3:127161.

8. Parker, P. J., F. B. Caudwell, and P. Cohen. 1983. Glycogen synthase from rabbit skeletal muscle: effect of insulin on the state of phosphorylation of seven phosphoserine residues in vivo. Eur. J. Biochem. 130:227-234.

9. Sheorain, V. S., H. Juhl, M. Bass, and T. R. Soderling. 1983. Effects of epinephrine, diabetes, and insulin on rabbit skeletal muscle glycogen synthase. J. Biol. Chem. 259:7024-7030.

10. Walkenbach, R. J., R. Hazen, and J. Larner. 1978. Reversible inhibition of cyclic AMP-dependent protein kinase by insulin. Mol. Cell. Biochem. 19:31-41.

11. Ingebritsen, T. S., and P. Cohen. 1983. Protein phosphatase: properties and role in cellular regulation. Science (Wash. DC). 221:331-338.

12. Ballou, L. M., and E. H. Fisher. 1986. Phosphoprotein phosphatases. In The Enzymes. P. D. Boyer and E. G. Krebs, editors. Vol 17. Academic Press, Inc., Orlando, FL. 311-361.

13. Okubo, M., C. Bogardus, S. Lillioja, and D. M. Mott. 1988. Glucose-6-phosphate stimulation of human muscle glycogen synthase phosphatase. Metab. Clin. Invest. 37:1171-1176.

14. Freymond, D., C. Bogardus, M. Okubo, K. Stone, and D. M. Mott. 1988. Impaired insulin-stimulated muscle glycogen synthase activation in vivo in man is related to low fasting glycogen synthase phosphatase activity. J. Clin. Invest. 82:1503-1509.

15. Chiasson, J. L., M. R. Dietz, H. Shikama, M. Wootten, and J. H. Exton. 1980. Insulin regulation of skeletal muscle glycogen metabolism. Am. J. Physiol. 239:E69-E74.

16. Chang, L. Y., and L. C. Huang. 1980. Effects of insulin treatment on the activities of phosphoprotein phosphatase and its inhibitors. Acta Endocrinol. 95:427-432.

17. Le Marchand-Brustel, Y., and P. Freychet. 1981. Regulation of glycogen synthase activity in the isolated mouse soleus muscle. Effect of insulin, epinephrine, glucose and anti-insulin receptor antibodies. Biochim. Biophys. Acta. 677:13-22.

18. Toth, B., M. Bollen, and W. Stalmans. 1988. Acute regulation of hepatic protein phosphatase by glucagon, insulin and glucose. $J$. Biol. Chem. 263:14061-14066. 
19. Nuttall, F. Q., M. C. Ganon, V. A. Corbett, and M. P. Wheeler. 1976. Insulin stimulation of heart glycogen synthase $D$ phosphatase (protein phosphatase). J. Biol. Chem. 251:6724-6729.

20. National Diabetes Data Group. 1979. Classification and diagnosis of diabetes mellitus and other categories of glucose intolerance. Diabetes. 28:1039-1057.

21. Goldman, R. F., and E. R. Buskirk. 1961. A method for underwater weighing and the determination of body density. In Techniques for Measuring Body Composition. J. Brozek and A. Henschel, editors, National Academy of Sciences, National Research Council, Washington, DC 78-89.

22. Guinovart, J. J., A. Salavert, J. Massague, C. J. Ciudad, E. Salsas, and E. Itarte. 1979. A new activity ratio assay expressing a high sensitivity to the phosphorylation state. FEBS (Fed. Eur. Biochem. Soc.) Lett. 106:284-288.

23. Thomas, J. A., K. K. Schlender, and J. Larner. 1968. A rapid filter paper assay for UDP glucose-glycogen glycosyltransferase, in cluding an improved biosynthesis of UDP- ${ }^{14} \mathrm{C}$-glucose. Anal. Biochem. 25:486-499.

24. Miller, T. B. 1979. Glucose activation of liver glycogen synthase. Insulin-mediated restoration of glucose effect in diabetic rats is blocked by protein synthesis inhibitor. Biochim. Biophys. Acta. 583:36-46.

25. Bergmeyer, H. U., editor. 1985. Methods of Enzymatic Analysis. RCH Publishers, Deerfield Beach, FL. 7:346-357.

26. Mandarino, L. J., K. S. Wright, L. S. Verty, J. Nichols, J. M. Bell, O. G. Kolterman, and H. Beck-Nielsen. 1987. Effects of insulin infusion on human skeletal muscle pyruvate dehydrogenase, phosphofructokinase, and glycogen synthase. J. Clin. Invest. 80:655-663.

27. Pain, V. M., E. C. Albertse, and P. J. Garlick. 1983. Protein metabolism in skeletal muscle, diaphragm, and heart of diabetic rats. Am. J. Physiol. 245:E604-E610.

28. Goheer, M. A., J. Larner, and R. T. Curnow. 1987. Long term regulation of glycogen metabolizing enzymes by insulin in $\mathrm{H} 4$ hepatoma cells. Mol. Cell. Biochem. 75:137-149.

29. Chan, C. P., S. J. McNail, E. G. Krebs, and E. H. Fisher. 1988.
Stimulation of protein phosphatase activity by insulin and growth factors in 3T3 cells. Proc. Natl. Acad. Sci. USA. 85:6257-6261.

30. Gilboe, D. P., and F. Q. Nuttall. 1972. The role of ATP and glucose-6-phosphate in the regulation of glycogen synthase D phosphatase. Biochem. Biophys. Res. Commun. 48:898-906.

31. Oron, Y., and J. Larner. 1980. Insulin action in intact mouse diaphragm. I. Activation of glycogen synthase through stimulation of sugar transport and phosphorylation. Mol. Cell. Biochem. 32:153-160.

32. Foulkes, J. G., P. Cohen, S. J. Strada, W. V. Everson, and L. S. Jefferson. 1982. Antagonistic effects of insulin and beta-adrenergic agonists on the activity of protein phosphatase inhibitor-1 in skeletal muscle of the perfused rat hemicorpus. J. Biol. Chem. 257:1249312496.

33. Huang, F. L., and W. H. Glinsmann. 1976. Separation and characterization of two phosphorylase phosphatase inhibitors from rabbit skeletal muscle. Eur. J. Biochem. 70:419-426.

34. Hiraga, A., and P. Cohen. 1986. Phosphorylation of the glycogen-binding subunit of protein phosphatase-1G by cyclic-AMP-dependent protein kinase promotes translocation of the phosphatase from glycogen to cytosol in rabbit skeletal muscle. Eur. J. Biochem. 161:763-769.

35. Yang, S. D., J. R. Vandenheede, and W. Merlevede. 1981. Identification of inhibitor-2 as the ATP-Mg-dependent protein phosphatase modulator. J. Biol. Chem. 256:10231-10234.

36. Holmes, C. F., D. G. Campbell, F. B. Caudwell, A. Aitken, and P. Cohen. 1986. The protein phosphatases involved in cellular regulation. Primary structure of inhibitor-2 from rabbit skeletal muscle. Eur. J. Biochem. 155:173-182.

37. Holmes, C. F., J. Kuret, A. A. Chisholm, and P. Cohen. 1986. Identification of the sites on rabbit skeletal muscle protein phosphatase inhibitor-2 phosphorylated by casein kinase-II. Biochim. Biophys. Acta. 870:408-416.

38. Young, A. A., C. Bogardus, D. Wolfe-Lopez, and D. M. Mott. 1988. Muscle glycogen synthesis and disposition of infused glucose in humans with reduced rates of insulin-mediated carbohydrate storage. Diabetes. 37:303-308. 